\title{
SJoP
}

\section{Practitioner report: Composing interaction: performativity in Mechanical}

\section{TIMOTHY COOPER}

The Scottish Journal of Performance

Volume 5, Issue 2; September 2018

ISSN: 2054-1953 (Print) / ISSN: 2054-1961 (Online)

Publication details: http://www.scottishjournalofperformance.org

To cite this article: Cooper, T., 2018. Practitioner report: Composing interaction: performativity in Mechanical. Scottish Journal of Performance, 5(2): pp.35-60.

To link to this article: http://doi.org/10.14439/sjop.2018.0502.03

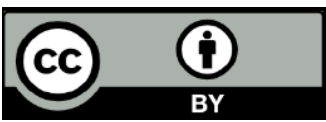

This work is licensed under a Creative Commons Attribution 4.0 International License. See

http://creativecommons.org/licenses/by/4.0/ for details. 
PRACTITIONER REPORT:

\section{Composing interaction: performativity in Mechanical}

TIMOTHY COOPER

DOI: 10.14439/sjop.2018.0502.03

Publication date: 30 September 2018

This paper explores the creation of Mechanical (2016), an interactive sound installation that explores the sound and physicality of old, worn and broken bicycle parts. In the paper I examine the question: what is the nature of the interaction in Mechanical? I will argue that the interaction elicits performative actions by the audience. I will contextualise this action through Sarah Rubidge's 'Performing installations' (2009). These performative actions are enabled by the specific nature of the interactive system which I will contextualise through Simon Emmerson's notion of meaningful response (2012; 2013). I will conclude that the specific nature of the interaction is characterised by the network formed by the system between audience members and the 'bikes', and the types of behaviour engaged in by the audience.

Keywords: electroacoustic music, sound-art, interactive, installation, performativity.

\section{Introduction}

In 2016 I created Mechanical, an interactive sound installation. The installation explores the sound and physicality of old, worn and broken bicycle parts. If the piece began as a way to save my Reynolds 531 Claude Butler Elite bike frame from the scrap heap, it grew into a piece where 
the interactive sonic experience became the key focus of the work.

Through examining the nature of the interactivity in Mechanical, I will argue that the work elicits performative actions by the audience. This will be contextualised through Sarah Rubidge's 'Performing Installations' (2009). These performative actions are enabled by the specific nature of the interactive system which I will contextualise through Simon Emmerson's notion of meaningful response (2012; 2013).

In the main body of the paper I will begin by giving a basic description of the installation, touching upon the set-up of the work, the nature of the audience, and the sound world of the work. I will follow this with a discussion of the nature of the interactive system describing the pertinent technical issues. The discussion will conclude with a contextualisation of the performative action of the audience.

I will discuss these issues from the point of view of the first presentation, the specific circumstances of which seemed to impact the work dramatically. The creation of the installation was supported by Cryptic, a Glasgow based company whose activity formerly focused on contemporary theatre work. Cryptic's output has transitioned to focus on sonic art that engages an audience visually as well as sonically. Their activity includes a biennial festival (SONICA-sonic art for the visually minded), their Cryptic Associates programme that 'nurtures and develops the next generation of artists' (Cryptic, 2016) and Cryptic Nights that provides a platform for emerging artists to present work. Their activity continues to support and produce performances, both in a traditional sense and in less traditional senses where artists might 'perform' a version of an installation. Mechanical was presented to an audience that holds these expectations from a Cryptic event and in a 
space regularly used by Cryptic for performances. I would suggest that this contributed to the particular character of the first presentations. In the first presentation, a relatively large number of audience members inhabited the installation at any one time (up to 40). This was a larger number than I had expected and allowed for interesting dynamics to emerge between the audience members. This dynamic contributed to audience members inhabiting the installation for longer than I expected (some audience members stayed for up to 40 minutes), which meant they could discover more about the different layers of the work than I had anticipated.

\section{Presenting Mechanical}

\section{The basic set-up}

Mechanical consists of three 'bikes' suspended on scaffolding poles (see figure 1). These are positioned in a triangle in the centre of the space. Each of the bikes has a handle attached to the crank arm, which can be used to drive the bicycle wheel. Attached to the bikes are microphones and dynamos; information is fed to a computer program in two ways; by the microphone about the sounds produced, and by a dynamo about the voltage generated when the wheel spins. 


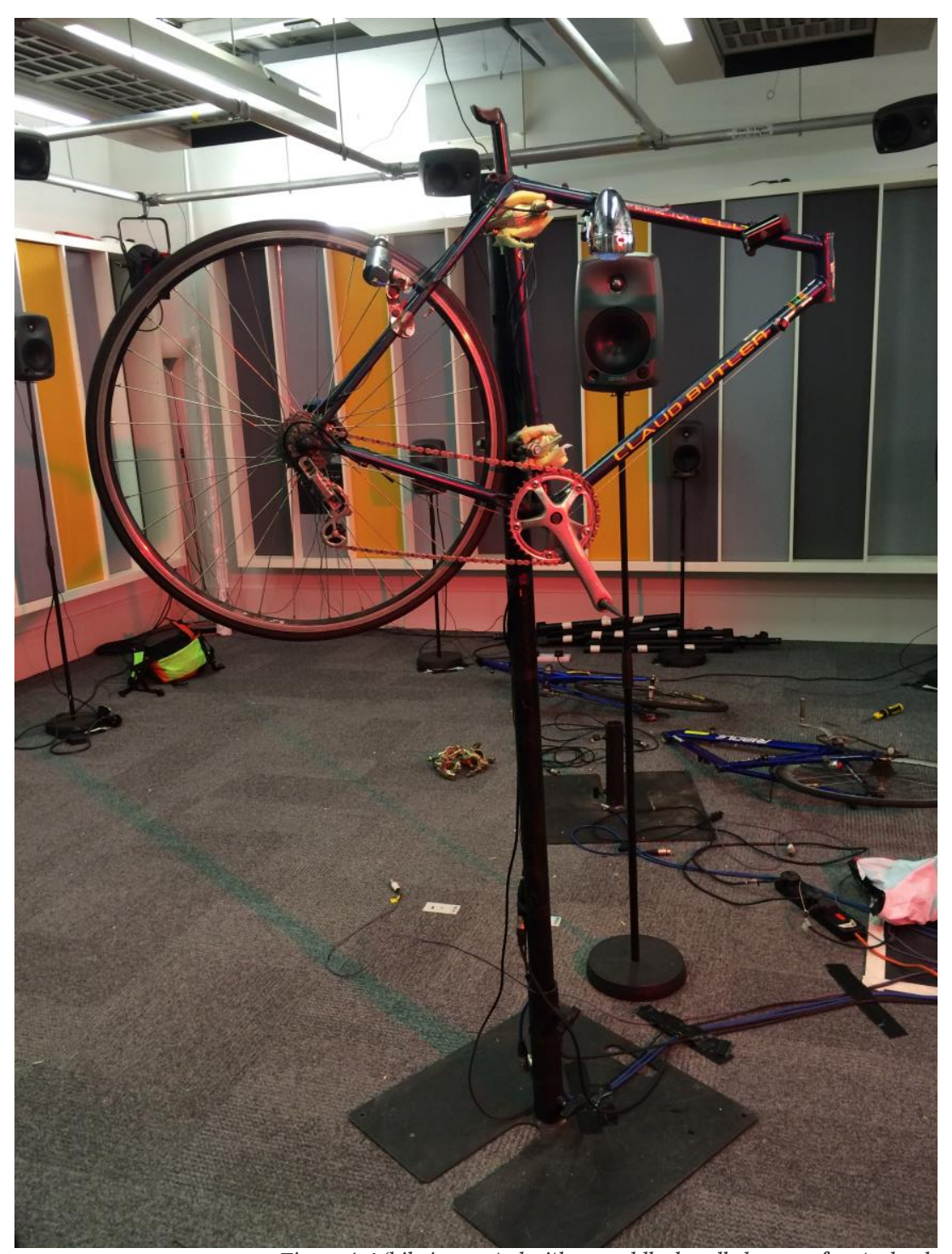

Figure 1: A 'bike' mounted with no saddle, handle bars, or front wheel. $A$ handle presented itself to the audience members.

A ring of eight loudspeakers surround the bikes and three individual loudspeakers are placed closely to each of the bikes. The loudspeaker ring plays back sounds that immerse the audience and that respond to the actions of the players (see figure 2). Overhead, two 'tweeter trees' (high frequency loudspeaker arrays) are suspended above the bikes. The 'tweeter trees' resemble the spokes of bicycle wheels (these are not shown in figure 2 to retain clarity in the image). 


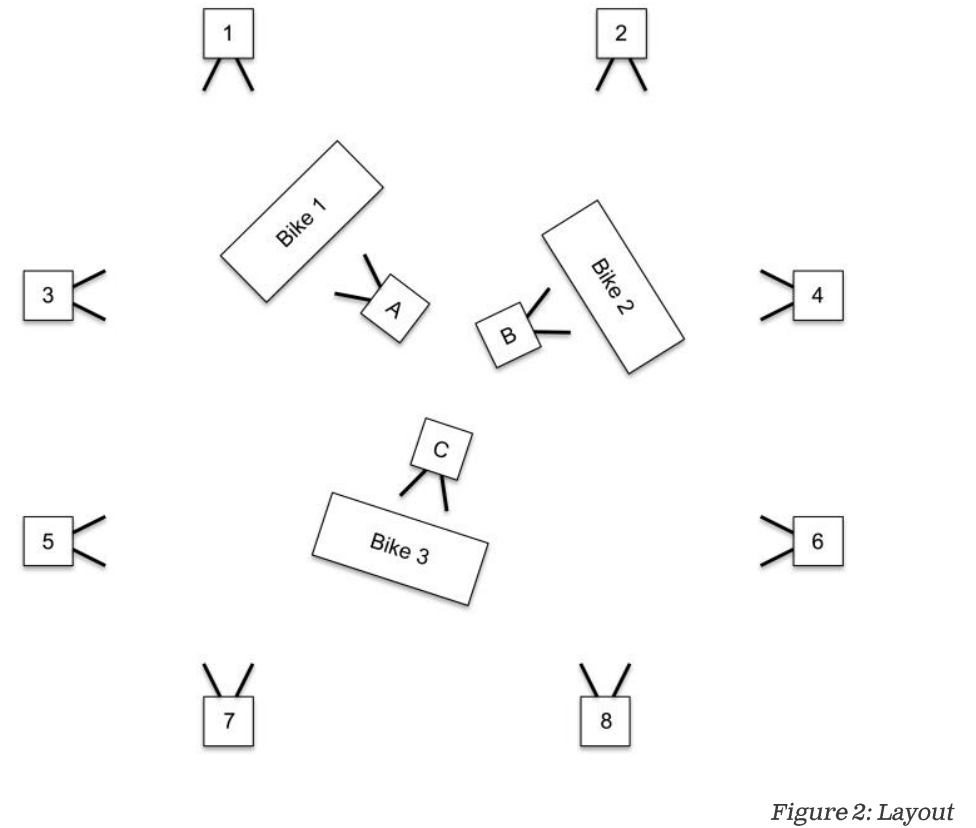

Mechanical was first presented at Cryptic Nights. The audience was invited to explore two different interactive installations following a live performance. The other interactive work was designed to be experienced by one person at a time, meaning that most of the audience moved directly into the space Mechanical inhabited.

Audience members interact with the bikes by turning the handle. The sound produced together with the voltage generated by the dynamo is analysed by a computer program that uses this information to trigger, and manipulate, pre-recorded sounds.

As the player(s) continue to interact with the bike(s), the program gives the player(s) greater control by allowing access to a new stream of sound, or by adapting the way the system responds to their input.

Mechanical is designed to be accessible to audience members who have no previous experience of the work. It is also designed with enough layers of complexity to 
encourage extended play and repeated play. On repeat visits I expect that audience members will discover deeper layers of connectivity between themselves and the sound world of the installation.

\section{Visually presenting the bikes}

Presenting the bikes as incomplete / non-functional is a sculptural decision. Whilst my focus was on the sound materials and the interactive system, it is impossible to ignore the bikes as physical objects in the installation space. The choices around mounting the bikes revolved around conceptual and practical aspects. On a practical level, the mounting needed to be sturdy enough that the participants felt 'permitted' to turn the crank vigorously, if they chose. Conceptually there were numerous options. The choice was made to mount the bikes in a visually simple way, attaching the frame securely to a black scaffolding pole and base. This emphasised the shapes of the individual bikes frames as aesthetic objects, rather than as functional (or in this case non-functioning) vehicles (figure 1).

\section{Layout of the space}

The space is laid out as in figure 2. The three players can look through their bike to see the other players. That is important when thinking about co-operative playing. Individual loudspeakers (A, B and C) are visible through the bike frame (figure 3 ) and these carry the sounds that are closely relatable to an audience member's action. A ring of eight loudspeakers, positioned above head height (numbered 1-8 in figure 2) frames the space. The materials sent to these loudspeakers create a sonic environment that immerses the audience. High frequency loudspeakers (not shown in figure 2) suspended over the audience carry the same material as the 8-channel array. However, the balance between the high array and the main array changes depending upon the level of activity in the space (this aspect 
will be expanded upon in a later section about co-operative play). When the work is dormant the level of the overhead loudspeakers is higher than the level of the main array. When the audience members turn the bike cranks, activating the work, the sounds descend into the main ring of eight loudspeakers.

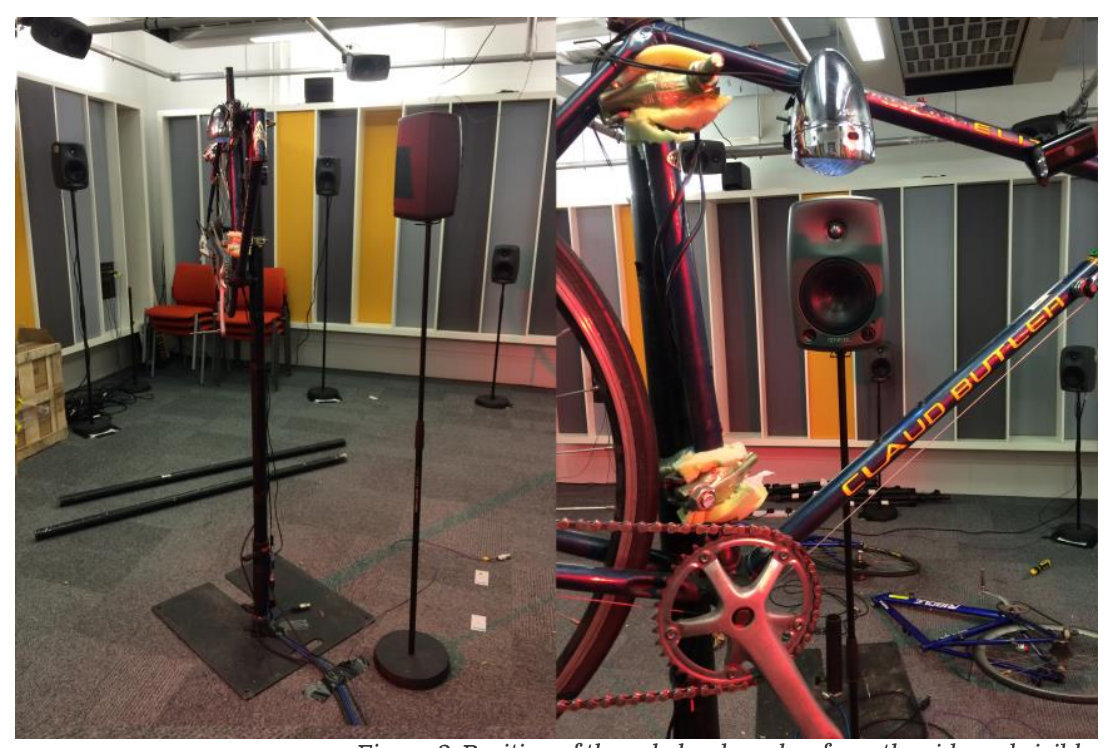

Figure 3: Position of the solo loudspeaker from the side and visible through the frame of the bike.

White and red bike lights are mounted on each bike and provide most of the light in the space. The installation space is also lit by a wash of red light from overhead.

Video 1 gives an impression of the installation experience. It is evident in the video that audience members explore the space and engage with the bikes and the audio gives a sense of the immersive sound world, using stereo playback.

https://youtu.be/f_MkogBJfaY 


\section{The audience}

In most installations one would not think of the visitors as being an 'audience'. In this work it is impossible to ignore the possibility of performance; if there are performers, who might they be performing to?

When engaging with the installation, on the surface it would seem there are two distinct ways to do this. For the purposes of this paper I will call these:

1. Player(s)-an audience member or members that are actively engaged in interacting with a bike physically and sonically.

2. Listener / onlooker(s)-an audience member or members that are exploring the space visually and sonically.

It is important to consider to what extent the player(s) consciously perform outwardly and to what extent that is encouraged by the work. From my perspective, I am uncomfortable with the idea that the work would require or encourage the player(s) to perform outwardly to the onlookers. Mechanical was created to encourage play and playfulness through sonic interaction. It would be an unfair expectation to assume that all audience members would be comfortable performing. In this respect, the player(s) are performing on the bikes rather than performing to the audience. However, if players choose to think of themselves as performers and they are performing to the other audience members, I am comfortable with them selfidentifying in this way.

Where the roles become more complex is when we consider how active the participation of the listener / onlooker(s) may be. From video 1, it is very clear that the audience is 
exploring the space, finding different vantage points from which to view / listen to the work. This is a more active role than it would seem at first.

In the context of the first presentation it is important to think about the way the audience members negotiated the space. There were $40+$ present and only three bikes. From my perspective I observed:

- Turn taking-the listener / onlookers seemed to wait patiently listening to and observing the interactions of the player(s).

- Sharing-there were moments where several players shared the same bikes, perhaps with one person making suggestions, or through one person turning the crank and the other changing gears.

- Exploring-most audience members spent most of their time listening / onlooking. Many of them seemed to explore the space thoroughly, perhaps moving from speaker to speaker, to listen from different parts of the space and take in different perspectives. Some audience members moved to different parts of the space from outside the ring of speakers to the space in between the bikes at the centre of the installation.

\section{Sound layers}

Within the work it is possible to hear up to 10 layers of sound. Six of these are directly interacted with by the player(s). 


\begin{tabular}{|c|c|}
\hline Layer & Bikes \\
\hline $\begin{array}{l}\text { Amplified Bike } \\
\text { Sounds } \\
\text { (3 layers) }\end{array}$ & $\begin{array}{l}\text { Each bike is amplified by a miniature condenser } \\
\text { microphone, which heightens the acoustic sound } \\
\text { of the bike. It also 'places' the sound of the bikes } \\
\text { within the solo loudspeaker. } \\
\text { Each bike also has a contact mic attached. These } \\
\text { microphones have quite an unnatural sound and } \\
\text { are not used throughout the work. They are only } \\
\text { used when the player turns the crank of their bike } \\
\text { forwards. }\end{array}$ \\
\hline $\begin{array}{l}\text { Solo Sounds } \\
\text { (3 layers) }\end{array}$ & $\begin{array}{l}\text { Each bike has access to a layer of solo sounds that } \\
\text { are projected only in their solo loudspeakers. The } \\
\text { relationship between the physical action and the } \\
\text { sonic result is extremely clear. }\end{array}$ \\
\hline $\begin{array}{l}\text { Textural } \\
\text { Gestures } \\
\text { (3 layers) }\end{array}$ & $\begin{array}{l}\text { Each bike has access to sounds with one of two } \\
\text { spatial identities: } \\
\text { 1. Sounds that fully occupy the 8-channel } \\
\text { array, with very little spatial movement. } \\
\text { 2. Sounds that are spatially active and } \\
\text { move (with spatial motions related to the } \\
\text { bicycles) around the 8-channel array. } \\
\text { With this layer, the relationship between the } \\
\text { physical action and the sonic result is more } \\
\text { disguised because this is shared amongst the } \\
\text { bikes. }\end{array}$ \\
\hline $\begin{array}{l}\text { Supporting } \\
\text { Texture } \\
\text { (1 layer) }\end{array}$ & $\begin{array}{l}\text { This layer provides a background for the other } \\
\text { sounds to be layered upon. Generally, this layer is } \\
\text { gesturally quite static and is usually quite specific } \\
\text { spectrally (mostly high, mid or low frequency) to } \\
\text { provide space for the other sounds. }\end{array}$ \\
\hline
\end{tabular}


All of the sounds in the work are derived from recordings I made of the Claude Butler bike and from the Time Trial in the 2017 British National Cycling Road Race.

The layer of solo sounds is both physically relatable and sonically relatable. They are reminiscent of bicycle chain sounds; these sounds create a bridge between the amplified sound of the bike and the other layers of sounds. One would not immediately relate the textural or supporting sounds to the bikes; however, through this careful orchestration and distribution of materials, these sonic relationships become apparent when the audience spends time within the installation.

\section{Interactivity}

In this section I will use Simon Emmerson's notion of meaningful response to contextualise the thinking that informed the design of the interactive system. In a series of articles, (1994; 1998; 2012; 2013), Emmerson has progressed our understanding of interactivity and liveness between performers and electroacoustic music. Initially, Emmerson described the experience of interactivity from the perspective of the composer and the audience (Emmerson, $1994 ; 1998)$. He has moved this thinking on to place the onus on the relationship between the performer and the electroacoustic materials.

When we discussed cause and interactivity... we did not specify who was perceiving (or trying to work out) the cause. It is surely the performer who must first and foremost feel a true response from a live electronic system (Emmerson, 2012, p.15). 
Emmerson describes 'The definition of appropriate and meaningful' relationships crossing boundaries 'from the technical cause to musical affect... The performer is key here and we've tended to neglect their feelings in many of our discussions' (ibid.).

Emmerson is discussing a trained musician performing with electroacoustic resources (whether these are live / real-time or fixed). The expert player(s) described are

...used to highly consistent cause-effect chains... $\mathrm{s} /$ he is particularly acute at listening and generating intricate and multiple feedback loops: listen > modify action > modify sound > listen... though usually not unconscious, often being the result of many hours of practice (Emmerson, 2013, p.5).

Here, Emmerson is describing the necessary conditions for meaningful response to occur. The modification of action in response to something the performer hears is critical in this process.

He also argues that it is not through the technical causes (whether these are programmed or composed) but through the experience of the performer that meaningful response manifests. Regardless of any programmed or composed relationships, the performer must feel that they are connected to the electroacoustic material. The relationship must be understandable and relatable. Critically, it must be a two-way relationship where the performers feel they can cause a response from the system and, in turn, feel prompted to respond to the system. Emmerson is arguing that relationships must be forged in the truest sense with perceived agency from both sides of the system. From this point of view, Emmerson is also suggesting that it does not 
make any difference whether the response is made by live manipulation of the sound or through pre-composing material.

In Mechanical, the players are different, as most of them will have no (or little) prior experience of playing this installation. Many of us will have experience of bicycles, but most of us will not have turned the drive chain of a bike by hand; in order to create these meaningful relationships, Mechanical is sensitive to this. I designed the system so that players can discover ways to play the bikes relatively intuitively. Instructions (perhaps akin to fingering charts for woodwind or brass instruments) are not provided; however, the 'instrument' itself is designed to guide the player, by rewarding certain kinds of activity. In order for this to happen, the system needs to provide the right kind of feedback for the player. It is through the design of the bikes and the invitation to play, and to continue playing, that the notion of meaningful response is enacted.

\section{Instrument design}

The interactive system is a network between the player(s) and the sounds produced. This is a technical system where the full potential of the installation will reveal itself through co-operative play. However, it extends out to the players as their input will be guided by the meaningful relationships they forge with their bikes and the impact that the input of the other player(s) will also have. Aspects of the network reveal themselves to individual players through their individual interactions, whereas other aspects only fully reveal themselves through co-operative playing.

Figure 4 shows how the information is transferred through the network relating to individual play: 
1. The player physically turns the crank of the bike (shown by the black arrows).

2. The energy produced (sonically and electrically) is transmitted to the interactive system (shown by the yellow arrows).

3. The interactive system analyses this information and makes appropriate decisions about which sounds to produce.

4. The sounds are sent to the loudspeakers which project them to the players (shown by the blue arrows).

This transfer of information relies on the system feeding back information sonically to the player(s), who adjust their action physically, creating a different sonic result.

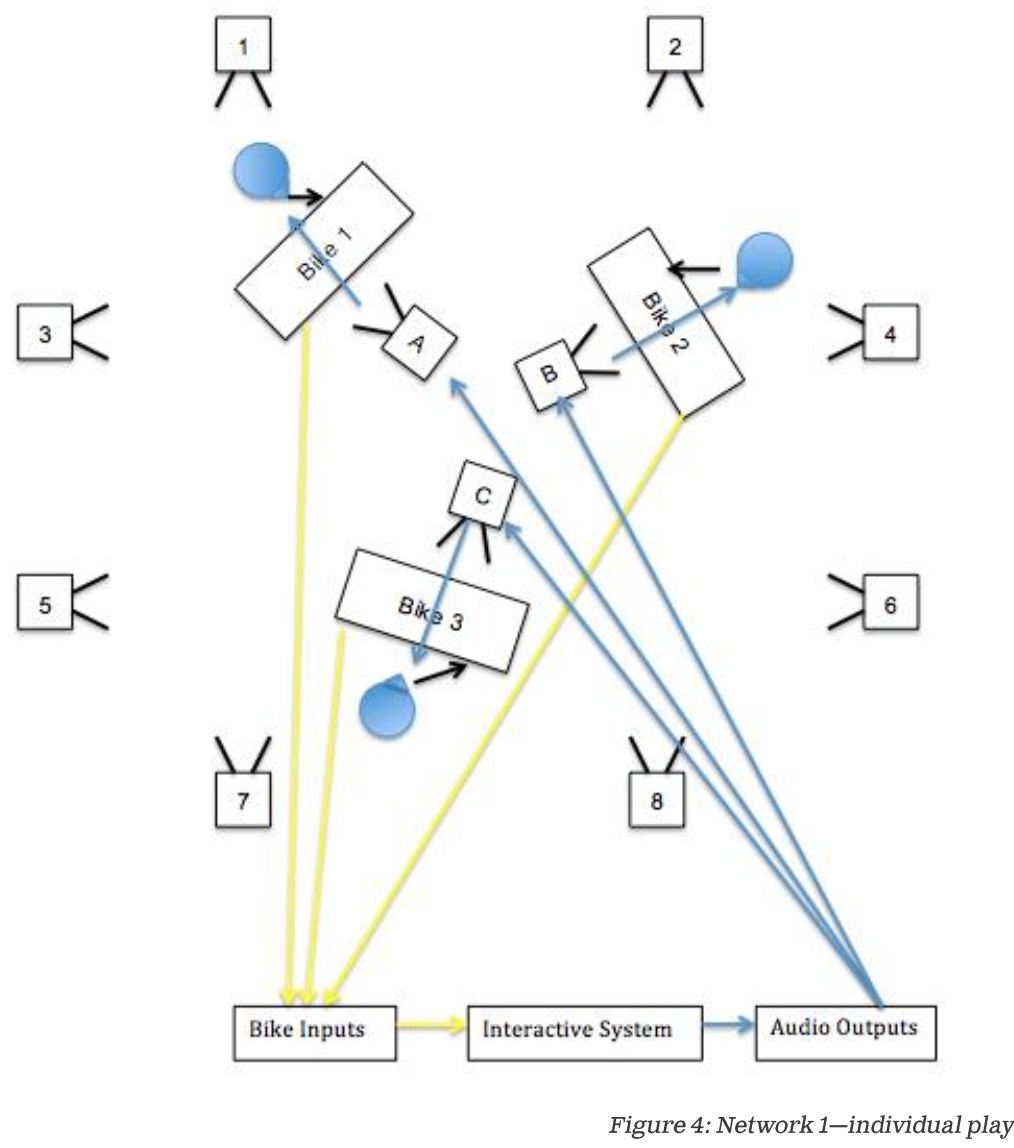

This becomes even more complex in figure 5 when the action and resulting sound produced by the player(s) is 
taken into account by the other players, together with the overall sound of the 8-channel system. Their behaviour in the first presentation began to change in order to adapt to the sound world evolving around them (shown by the green lines).

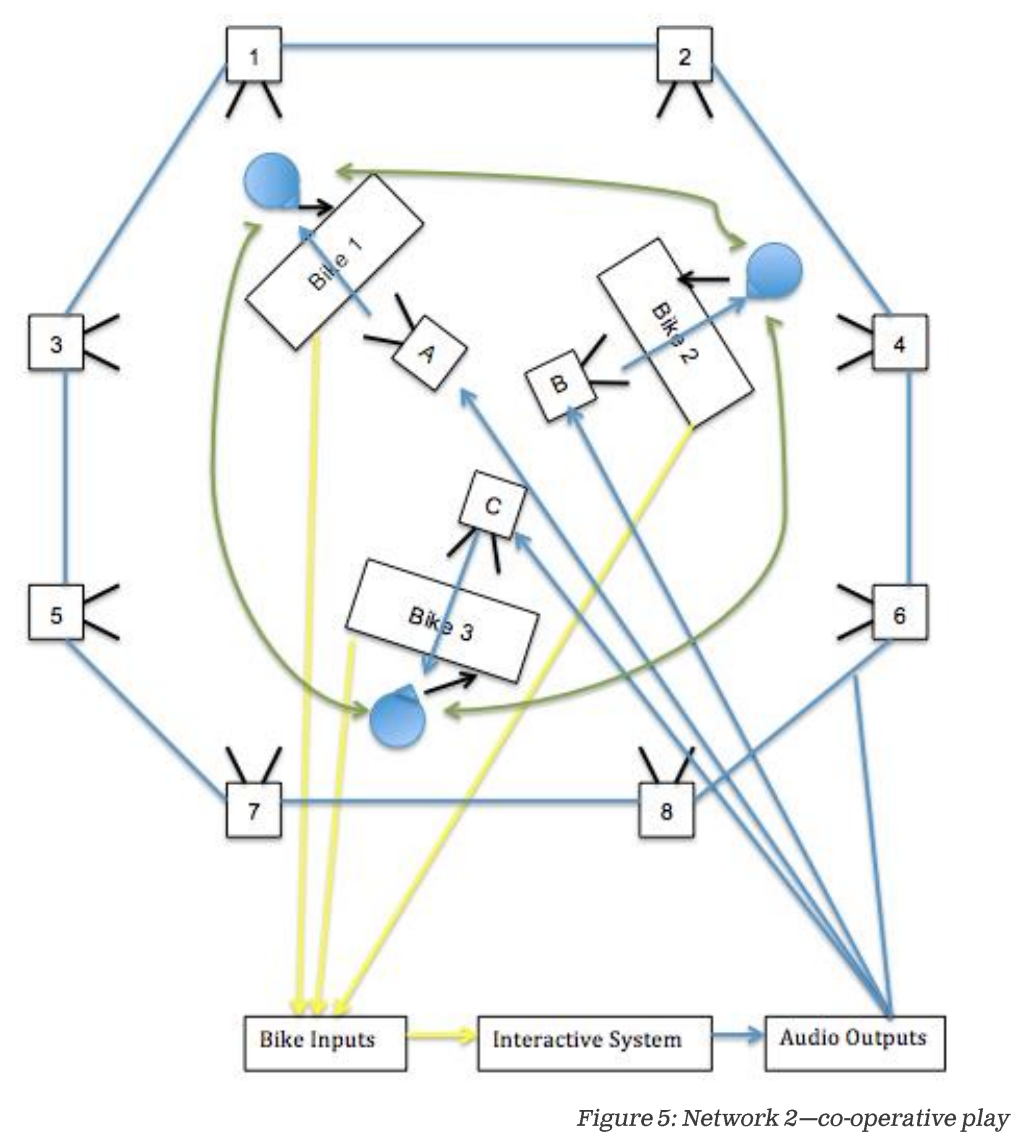

\section{Individual play}

In early work on the piece I thought about the notion of the player controlling the sounds. This led to ideas surrounding gaming and gameplay as potential models for developing the system. As the compositional process progressed it became clear that the bike's interface had moved beyond the idea that the player was, or even could be in control. The complexity of the bike as a tactile object became increasingly important through the compositional process. The sensation of turning the crank is not nearly as simple as it might seem. The different sensations one engages in when turning the crank forwards or backwards reveals 
different kinds of energy required to sustain the motion of the bicycle mechanics. This is reflected in the types of sounds accessed by the player(s). When winding backwards the potential dynamic, timbral and pitch range of the sounds produced are more limited than when winding forwards. The audible result here articulates the difference in the tactile sensation.

The complexity of the physical interface created significant issues when designing the interactive system. Testing early drafts of the system on 'audiences' resulted in dramatically re-imagining the nature of this network. The test program did not create meaningful relationships between the players and the bikes. It failed to meet Emmerson's condition that meaningful response must be felt first and foremost by the player (Emmerson, 2013). The sounds were too complex and layered for the listener to be able to relate their actions to the resulting sound. There were several factors here; the original system:

1. Was always sonically active. The idea was that the player influenced a stream of sound that already existed, rather than their action generating sounds that weren't already present.

2. Mapped 'control data' onto many parameters, which led to a level of complexity that was extremely hard to follow. Different layers had significantly different mappings (one sound might be pitch shifted up as more energy is put into the system whilst another's pitch would get lower).

3. Used two loudspeakers with each bike; however, the lack of specific localisation meant that the player found it hard to track the impact of their action upon the installation because they didn't know the 'location' of their sound(s). Most instruments are very easy to locate sonically and it seemed to make 
sense to use just one loudspeaker to really place the sound within an individual loudspeaker.

The invitation to play and the invitation to continue to play

The issues raised during testing led me to re-evaluate what aspects should define the piece. This led me to compose, more carefully, two specific and critical moments in the interaction between player and bikes:

1. The invitation to play.

The invitation to play is part visual and part sonic. There is no pedal attached to the crank arm. The use of a handle is a conscious, visual attempt to encourage an audience member to turn the crank and therefore 'play' a bike (figure $6)$.

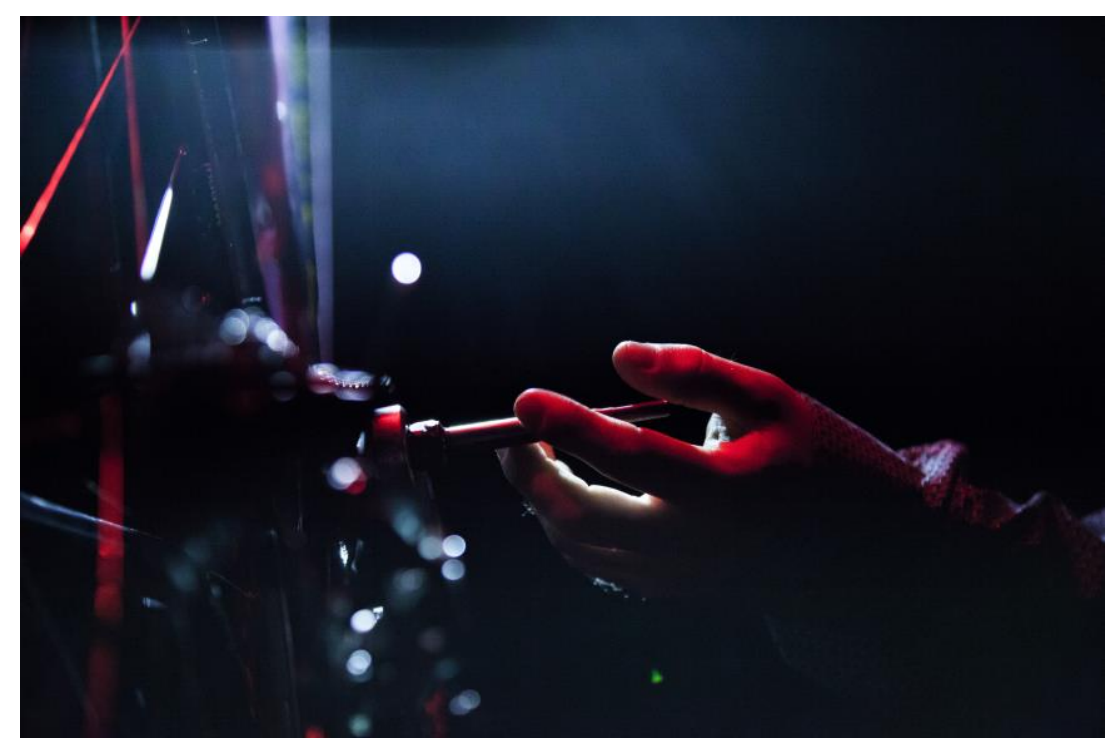

Figure 6: Audience member reaching for a handle. Photograph courtesy of Robert McFadzean. 
Localising the individual bike sounds in mono loudspeakers contributed greatly to the forging of a relationship between the player and their bike. Amplifying the acoustic sound of the bike to a level that draws the player's attention forwards, towards that loudspeaker, helps the player to relate to the sounds projected by their solo speaker.

The invitation to play is reinforced by a clear one-to-one relationship between the player and the bike. As soon as a player begins to turn the crank, simple, relatable sounds are produced. This moment is heightened by triggered sounds that articulate the initial interaction, giving the player confidence that their action produced the resulting sounds.

2. The invitation to continue to play.

The invitation to continue to play is made by the system responding to the action of a player. There are two aspects to consider here. Firstly, the natural variation in the player's action will result in slightly different responses from the system, even when they perform exactly the same action (of course, performing precisely the same action is impossible). Simon Waters argues that classical music instruments 'are increasingly designed to have predictable linear behaviours' (Waters, 2013, p.123). In this context, he is discussing instruments designed for more traditional music making where (relatively) exact repeatability is desired. This is not possible in Mechanical because of the complexity of the bike as an interface.

Secondly, the system is designed to progress with the player. As the player continues to play, the system's response is programmed to change. Each time a player stops turning the crank momentarily, the system will 'progress', giving the player access to further possibilities. 
At each point the system 'progresses' it makes a choice either to:

1. Give the player a new sound to play in addition to the sound(s) they already have access to.

2. Change the way the data is mapped on the sound in one of two ways:

a. Change the mapping of a parameter they are already engaged with.

b. Map the data onto an additional parameter.

At each pause between actions, the system makes the same choices: to add sounds or to progress a sound. Each bike can access to up to five sounds. The nature of the system is such that if a player plays for long enough they will also get full access to all five sounds, but that they will almost never have precisely the same control over these sound types. Figure 7 expresses progression routes visually and video 2 shows this happening with a solo player and with two players.

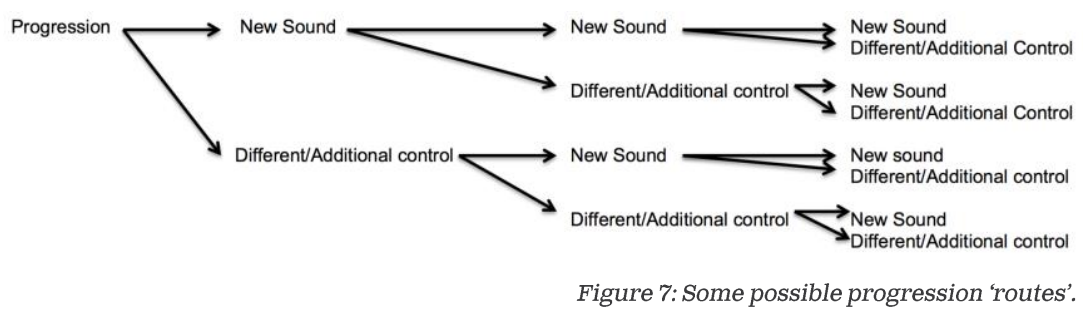

https://youtu.be/WPhu8h6UBfo

\section{Co-operative play}

Co-operative play affects the 8-channel sonic environment. The individual data streams are mapped to: 
1. The overall volume of the multichannel system. When the system is dormant the overall sound of the installation is relatively low. When it is activated through one or more bikes being played the overall volume increases. Each bike has access to 8-channel textures that are projected around the audience. These generally exhibit much higher energy than the solo sounds or are very specific spectrally (like a very low rumble). It is expected not that the player would be immediately aware of their relationship with these sounds, but that through continued play their relationship with these sounds becomes apparent. At this point the relationship that they forge with these sounds will affect the way the player engages with the system. As they become aware of additional layers of sound, or the energy they input is mapped onto more parameters, they can play in a more conscious way not only with the simple one-to-one mappings but also with the more apparently complex sounds.

2. The way the sounds occupy the space. When the players co-operatively put more energy into the system the sounds descend into the main ring of eight loudspeakers. This makes the sounds more immersive as they are no longer spatialised principally above the audience. Another aspect to this is the way the sounds occupy the 8-channel space. If only one player is putting lots of energy into the system then the 8-channel materials will be loudest in their part of the space. In order for the space to be fully activated then all three players need to put lots of energy into the system (shown in figure 8).

3. Spectral density. With less energy in the system the multi-channel sounds are filtered to make the overall sound brighter, and therefore lighter in texture. When more energy is input the filter is automated to increase the low-mid and low frequency sound, which makes the texture heavier, more immersive and more 'environmental'. 


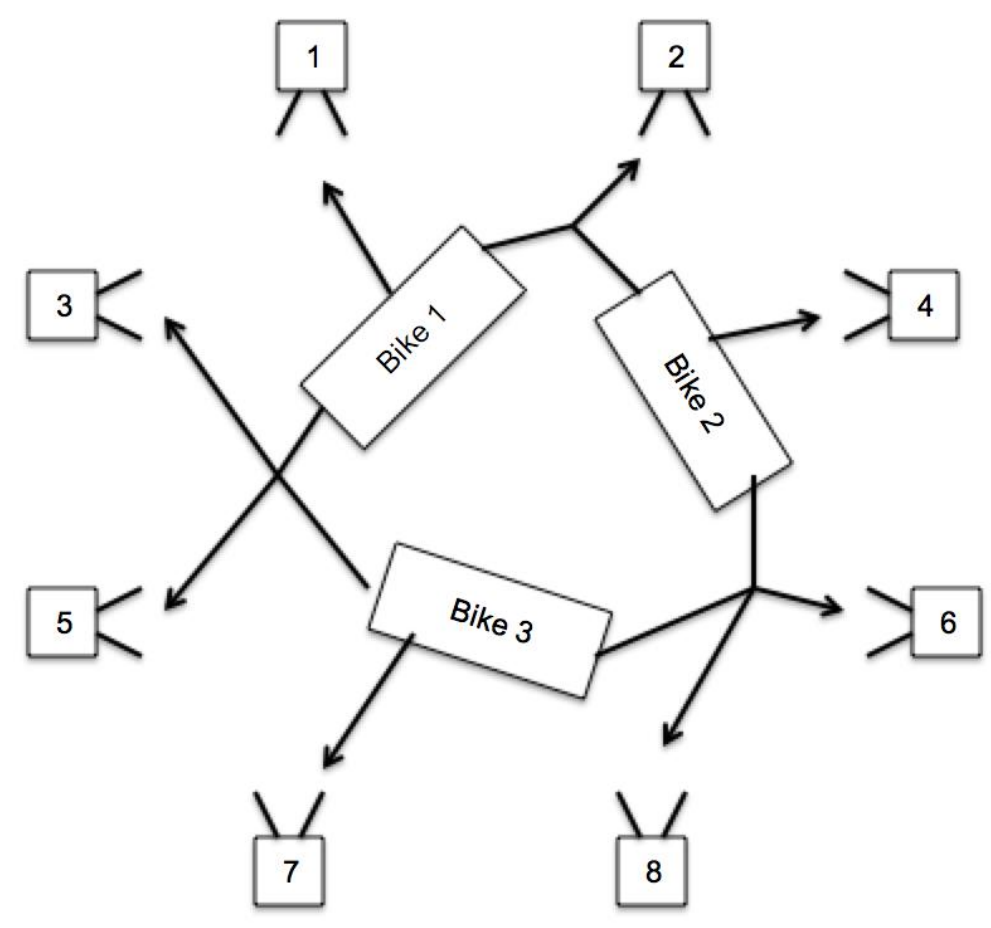

Figure 8 shows that channels 1,4 and 7 are directly controlled by the bike that is closest and channels 2, 3, 5, 6 and 8 are controlled co-operatively by the two bikes

that are closest. If one bike is being played then the speakers around it will become louder. In order for the full potential of the system to be realised all three players need to input high energy.

\section{Performativity}

In this part of this paper I will set out the specific conditions of the work that define the audience action as performative, based on three key aspects of the work.

1. Visitors' Behaviour.

Sarah Rubidge argues that '...performative installations, which acknowledge the philosophical implications of the term performative frequently, reveal themselves and their content... through the visitor's behaviour' (Rubidge, 2009, p.366). This is a critical aspect in Mechanical. Without the performative action of the audience the work will remain 
dormant, and it is through this action that the sounds that form the fabric of the work itself are produced.

2. Improvisation, not restored behaviour.

Rubidge, referencing J.L. Austin, argues that performative acts bring 'a new state of affairs into being' (Rubidge, 2009). This is an important part of the nature of Mechanical. Through engaging with the installation, the audience articulates the installation space with sounds with which they are in a direct relationship. They are, through their action, bringing a new state of affairs into being because of the nature of this relationship where the interactive system responds to the behaviour of the audience. This kind of activity is by definition a kind of improvisation that Rubidge argues is a key condition for an act to be performative.

Richard Schechner discusses the notion of restored behaviours. He describes this as 'actions that are not-forthe-first time; that are prepared or rehearsed' (Schechner, 2013, p.29). He argues that all behaviours are restored in the sense that we are never performing an action for the first time. All actions are at the very least learnt from observing the behaviour of another. However, he goes on to discuss the particular nature of restored behaviours in a theatrical context. In contemporary performance it is common for theatrical performances not to explore scripted narratives, but for the artist to present a heightened version of their own behaviour. In this area of artistic work they often make work that highlights ordinary behaviours and activities and presents them in a way that becomes performance, rather than being a traditional performance. This is significantly different to an actor learning a part and relates much more strongly to Mechanical in the way the work behaves. In this context a performer may be concerned with 'doing not with meaning. [S/he] does not start with an attempt to represent 
or signify. [S/he] acts rather than acting' (Garoian quoted in Rubidge, 2009, p.366).

In applying this thinking to Mechanical, I would argue that the behaviour of the audience cannot be restored in the traditional sense of performing a pre-existing work that is re-presented to the other audience members. The audience is confronted with a work that continually adapts to their behaviour, provoking them to continue their engagement and presenting them with constantly changing possibilities.

3. No performance ritual.

Certain events are performances and other events less so. There are limits to what "is" performance... Something "is" a performance when historical and social context, convention, usage, and tradition say it is... (Schechner, 2013, p.38).

In no sense does Mechanical engage with performance ritual. The ordinary boundaries between performer and audience are dissolved, as the audience members become active participants in the work. The players are not performing, they are being playful and explorative with the interactive system.

\section{Conclusion}

It is through the interactive network that the possibility for performative action emerges. The term performative was not central to the creation of the work, but provides a useful lens through which to view the activity of the audience in the installation. Moving the work beyond the notion of 'control' was extremely important in terms of forming meaningful relationships between the player(s) and the bike(s). 
That the installation rewards extended play is critical to the success of this work in the context of the first presentation. Without the multi-layered network I have outlined above, which relies on the visitors' action, Mechanical could not engage an audience for an extended period and therefore would not elicit performative action from the audience.

Whilst I have focused on the particular circumstances of the first presentation, I would like to contrast this with the setting of the second presentation during BEAST FEaST 2017 at Birmingham University. In this second presentation, the work was open for longer periods of time and fewer people entered the work at one time. This seemed to affect the amount of time that audience members spent in the installation. As they did not have to navigate the space waiting to take turns on the bikes, they were unable to watch and listen to the actions of other players. It seemed to me that the level of engagement was much closer to what I had expected. I had anticipated when creating the work that audience members would play with one or two of the bikes for relatively short periods (1-3 minutes and staying in the work for 5-10 minutes) and would access some of the complexity of the work but not access or understand the more abstracted layers.

This suggests that, at its richest, the nature of the interaction in Mechanical is performative, and that the number of audience members engaging with the installation has a dramatic effect on the work. In the presentation at Cryptic Nights, it was clear that because the audience played for extended periods of time, the deeper layers of the interactive system became more apparent. This allowed the players to create meaningful relationships between themselves and the sounds they produced, but also to create meaningful relationships with the other players. It is through extended play (improvisation, experimentation, collaboration)-and not performing outwardly towards the 
'audience'-that the nature of the interactive system reveals itself.

\section{Acknowledgements}

I would like to acknowledge the kind support of Cryptic who supported a residency period at Cove Park which was invaluable for the creation of the work. I would also like to thank Willy Bain from Bicycle Repair for his work on the bikes, Jason Lim for work done on the interactive system, and my kind test audience members (too many to name) for helping me to shape the final version of the work. I'd also like to thank colleague Steve Macluskie from the School of Drama, Dance, Production and Film at the Royal Conservatoire for his help in finding a way to suspend the bikes that was visually striking and suitably sturdy.

Finally, I would like to thank my PhD supervisors Professor Alistair MacDonald and Dr Diana Salazar for their invaluable guidance through the creation of the work.

\section{References}

Cryptic., 2016. Associate Artists. [online] Available at: 〈http://www.cryptic.org.uk/cryptic-associates/〉 [Accessed 1 March 2017].

Emmerson, S., 1994. 'Live' versus 'real-time'. Contemporary Music Review, 10(2), pp.95-101.

Emmerson, S., 1998. Acoustic/electroacoustic: the relationship with instruments. Journal of New Music Research, 27(1-2), pp.146-164.

Emmerson, S., 2012. Location - dislocation - relocation ('Where is live electronic music?'). In: Proceedings of the IV Seminar - Music Science Technology: Frontiers and Ruptures. São Paulo (Brazil), pp.7-16.

Emmerson, S., 2013. Rebalancing the discussion on interactivity. In: Proceedings of the Electroacoustic Music Studies Network Conference. Electroacoustic Music in the Context of Interactive Approaches and Networks. Lisbon.

Rubidge, S., 2009. Performing installations. In: Contemporary Choreography: A Critical Reader. London: Routledge, pp.362-378. 
Schechner, R., 2013. Performance studies: an introduction. 3rd ed. London: Routledge.

Waters, S., 2013. Touching at a distance: resistance, tactility, proxemics and the development of a hybrid virtual / physical performance system. Contemporary Music Review, 32(2-03), pp.119-134.

\section{About the author}

TIMOTHY COOPER is a composer and performer of electroacoustic music. In his music he explores new contexts for the sounds he works with. He uses microphones as sonic microscopes, and loudspeakers to amplify and heighten the qualities of the sounds he records. Recent projects include the site-responsive installation Tide Times made with Laura Bissell, and Breathing Space for tuba and electronics composed for Danielle Price.

Tim is a PhD candidate at the Royal Conservatoire of Scotland, supervised by Professor Alistair MacDonald and Dr Diana Salazar. He lectures at the Royal Conservatoire of Scotland and at Edinburgh College. 